\title{
Simbióticos e monensina sódica no desempenho e na qualidade da carne de novilhas mestiças Angus confinadas
}

\author{
Fábio Garcia Ribeiro(1), André Mendes Jorge ${ }^{(1)}$, Caroline de Lima Francisco(1), André Michel de Castilhos ${ }^{(2)}$, \\ Cristiano Magalhães Pariz ${ }^{(2)}$ e Maurícia Brandão da Silva ${ }^{(1)}$
}

\begin{abstract}
(1)Universidade Estadual Paulista (Unesp), Faculdade de Medicina Veterinária e Zootecnia, Departamento de Produção Animal, Distrito de Rubião Júnior, s/no, Caixa Postal 560, CEP 18618-970 Botucatu, SP, Brasil. E-mail: fabgarib@gmail.com, andrejorge@fmvz.unesp.br, carolinelimafrancisco@gmail.com, bernezoo@yahoo.com.br ${ }^{(2)}$ Unesp, Departamento de Melhoramento e Nutrição Animal, CEP 18618-970 Botucatu, SP, Brasil. E-mail: michel@fmvz.unesp.br, cmpzoo@gmail.com
\end{abstract}

Resumo - O objetivo deste trabalho foi avaliar o efeito da inclusão de simbióticos e de monensina sódica em dietas sobre o desempenho, as características de carcaça e a qualidade da carne de novilhas mestiças Angus em confinamento. Utilizou-se um delineamento inteiramente casualizado, com 64 animais distribuídos em quatro tratamentos: controle, dieta sem suplementação; dieta suplementada com simbióticos; dieta com monensina sódica; e dieta com simbióticos e monensina sódica. A dieta com monensina sódica e a dieta com simbióticos e monensina sódica proporcionaram maior ganho de peso médio diário e ganho de peso vivo total, além de melhorar a eficiência alimentar e biológica dos animais em comparação ao controle. A dieta de simbióticos, a de monensina e a de simbióticos com monensina sódica ocasionaram a redução da ingestão de matéria seca, elevaram o peso do filé da costela e os teores de lipídeos totais na carne. A dieta com simbióticos proporcionou a redução da força de cisalhamento da carne em relação ao controle. A inclusão de simbióticos, com ou sem monensina sódica, na dieta de novilhas mestiças Angus confinadas, beneficia o desempenho animal e algumas características físico-químicas da carne.

Termos para indexação: bovino de corte, composição química da carne, eficiência alimentar, força de cisalhamento, ganho de peso vivo.

\section{Synbiotics and sodic monensin on performance and meat quality of Angus crossbred heifers on feedlot}

\begin{abstract}
The objective of this work was to evaluate the effect of inclusion of synbiotics and sodic monensin on the performance, carcass characteristics, and meat quality of Angus crossbred heifers on feedlot. A completely randomized block design was carried out with 64 animals distributed in four treatments: control, a diet without supplementation; a diet supplemented with synbiotics; a diet with sodic monensin; and a diet with synbiotics and sodic monensin. The diet with sodic monensin and the diet with synbiotics and sodic monensin increased the average daily gain and total live weight gain, besides improving the feed and biological efficiency of animals compared to control treatment. The diet with synbiotics, with sodic monensin, and with synbiotics and sodic monensin decreased dry matter intake, and increased the rib fillet weight (noix) and the total lipid concentration in the meat. The diet with synbiotics facilitated the reduction of meat shear force compared to control treatment. The inclusion of synbiotics, with or without sodic monensin, in diet of Angus crossbred heifers, improves animal performance on feedlot and some physicochemical characteristics of meat.
\end{abstract}

Index terms: beef cattle, chemical composition of meat, feed efficiency, shear force, body weight gain.

\section{Introdução}

A atividade pecuária bovina é um dos setores mais importantes do agronegócio brasileiro e da economia nacional. O Brasil é conhecido pelo alto potencial de produção no setor pecuário por possuir, atualmente, o maior rebanho comercial de bovinos, que classifica o país como o maior exportador e o segundo maior produtor de carne bovina do mundo (Estados Unidos, 2015). A utilização de animais provenientes de cruzamento industrial é uma ferramenta importante nesse contexto, pois contribui para o aumento da produção e melhora a qualidade da carne exportada, por explorar os efeitos da heterose ou vigor híbrido. Os efeitos sobre os aspectos produtivos e qualitativos da carcaça de machos provenientes desses cruzamentos 
são bem conhecidos (Prado et al., 2008; Ito et al., 2012), porém, quanto às fêmeas, ainda é necessário um número maior de estudos que avaliem a produtividade e as características de carcaça de animais provenientes de cruzamento, em fase de terminação.

Em algumas regiões do Brasil, parte significativa da carne comercializada provém da produção de novilhas (Coutinho Filho et al., 2006). Assim, para atender a demanda do produto, garantir a permanência do produtor na cadeia produtiva e estabelecer o equilíbrio do setor, é necessário o uso de recursos tecnológicos como a genética e o manejo nutricional adequados ao sistema de produção utilizado.

Assim, tem aumentado, ao longo dos últimos anos, a utilização de dietas para animais em confinamento, com alta inclusão de concentrado e de aditivos (Graminha et al., 2007) para otimizar a fermentação ruminal e reduzir os índices de distúrbios digestivos (Ladeira et al., 2014). A monsensina sódica é o aditivo mais utilizado e estudado mundialmente em bovinocultura, porém, há relatos promissores relacionados ao uso de prebióticos, probióticos e enzimas na dieta de bovinos de corte (Stein et al., 2006). A combinação desses aditivos moduladores pode apresentar efeitos aditivos ou sinérgicos, o que os caracteriza como simbióticos, e sua utilização pode ser realizada para potencializar a resposta animal conforme a ação de cada aditivo (Raizel et al., 2011). A utilização de simbióticos ou sua associação à monensina pode favorecer a saúde intestinal, maximizar a absorção de nutrientes no rúmen e no intestino e, consequentemente, melhorar o desempenho dos animais.

O objetivo deste trabalho foi avaliar o efeito da inclusão de simbióticos e de monensina sódica em dietas sobre o desempenho, as características de carcaça e a qualidade da carne de novilhas mestiças Angus em confinamento.

\section{Material e Métodos}

O trabalho foi conduzido de acordo com as normas da Comissão de Ética no Uso de Animais (CEUA), da Faculdade de Medicina Veterinária e Zootecnia, Universidade Estadual Paulista, Campus de Botucatu, sob protocolo $n^{\circ} 117 / 2012$-CEUA.

$\mathrm{O}$ experimento foi realizado na Agropecuária Fazenda Paraíso, no Município de São Miguel Arcanjo, $\mathrm{SP}$, a $23^{\circ} 52^{\prime} 50^{\prime \prime} \mathrm{S}, 48^{\circ} 0^{\prime} 38^{\prime \prime} \mathrm{W}$ e à altitude média de
$700 \mathrm{~m}$, com clima subtropical úmido - Cwa, conforme Köppen-Geiger.

Utilizaram-se 64 novilhas mestiças, com predominância das raças britânicas Aberdeen Angus e Red Angus, divididas em quatro grupos homogêneos (16 animais por tratamento), de acordo com o peso vivo inicial. Os animais foram alocados em confinamento descoberto, com pavimentação de concreto, comedouros e bebedouros coletivos. Cada tratamento foi distribuído em baia coletiva de $11,20 \mathrm{~m}$ de frente e $12,00 \mathrm{~m}$ de fundo, no total de $134,40 \mathrm{~m}^{2}$.

Utilizou-se o delineamento experimental inteiramente casualizado, com 16 animais por tratamento, em que a repetição constituiu-se dos animais. Os tratamentos foram: controle (C), que é a dieta sem suplementação; dieta com simbiótico (S); dieta com monensina sódica (M); e dieta com simbiótico e monensina sódica $(\mathrm{S}+\mathrm{M})$.

O produto com o simbiótico utilizado é composto de uma mistura de Saccharomyces cerevisiae, Lactobacillus acidophilus, Enterococcus faecium, Bacillus subtilis, celulase, hemicelulase, xilanase, mananoligossacarídeo, levedura inativa, carbonato de cálcio e dióxido de silício (Sainz, 2010). Utilizaramse 2 gramas do produto com simbiótico e $150 \mathrm{mg}$ de monensina sódica por animal por dia.

As dietas foram fornecidas duas vezes ao dia-às 8:00 e às 16:00 h-, divididas em 40 e $60 \%$ do fornecimento total, respectivamente. As sobras foram coletadas diariamente e pesadas para permitir sobra de 5\% que era corrigida duas vezes por semana. Os animais permaneceram 112 dias em confinamento, em que os primeiros 28 dias foram utilizados para adaptação às dietas. O período experimental consistiu de 84 dias, divididos em três períodos de 28 dias. As dietas foram formuladas com uso do programa NRC (2000) nível 2, para o ganho de peso de $1,6 \mathrm{~kg}$ por dia. A simulação ruminal foi realizada pelo programa computacional Large Ruminant Nutrition System (LRNS), com base no Cornell Net Carbohydrate and Protein System (CNCPS) (Cornell University, Ithaca, NY, EUA), versão 5.0, para bovinos de corte.

Os ingredientes utilizados e a composição nutricional das dietas, no período de adaptação e nos três períodos experimentais, se encontram na Tabela 1. A composição bromatológica das dietas foi determinada conforme Silva \& Queiroz (2002). 
Os teores de nutrientes digestíveis totais (NDT) foram estimados conforme a equação proposta por Weiss, adotadas pelo National Research Council (NRC) dos Estados Unidos (Nutrient..., 2001). Diariamente, os alimentos foram pesados antes do fornecimento aos animais e, a cada dois dias, anteriormente ao primeiro arraçoamento, os cochos eram limpos e as sobras pesadas e anotadas para ajuste do fornecimento da dieta total e cálculo da ingestão diária de matéria seca (IMS) e eficiência alimentar (EA).

Após o período de adaptação, as novilhas foram pesadas individualmente, em jejum alimentar e hídrico de 12 horas, para a obtenção do peso vivo inicial (PVI). A mesma metodologia foi utilizada para a determinação do peso vivo final (PVF). O ganho médio diário (GMD) foi determinado pela diferença entre o PVF e o PVI dos animais, dividido pelo número de dias do experimento (84 dias). A EA foi calculada pela razão entre o GMD e a IMS, conforme a equação: $\mathrm{EA}=(\mathrm{GMD} / \mathrm{IMS})$.

Os animais foram transportados, em jejum de dieta sólida, e abatidos em conformidade com os métodos para abate humanitário (Brasil, 2000), em frigorífico localizado a $265 \mathrm{~km}$ do local experimental. Após o

Tabela 1. Composição percentual dos ingredientes e características nutricionais da dieta, durante o período de adaptação de 28 dias e do período experimental de 84 dias (56, 84 e 112 dias).

\begin{tabular}{|c|c|c|c|c|}
\hline \multirow[t]{2}{*}{ Ingredientes } & \multicolumn{4}{|c|}{ Período } \\
\hline & 28 & 56 & 84 & 112 \\
\hline \multicolumn{5}{|l|}{ Ingredientes (\% de MS) } \\
\hline Silagem de milho & 37,52 & 30,06 & 28,67 & 26,07 \\
\hline Milho moído - peneira de $6 \mathrm{~mm}$ & 44,02 & 49,55 & 50,84 & 53,22 \\
\hline Soja-grão & 15,63 & 17,54 & 17,66 & 17,89 \\
\hline Núcleo mineral $^{(1)}$ & 1,70 & 1,58 & 1,51 & 1,46 \\
\hline Ureia & 1,13 & 1,27 & 1,31 & 1,36 \\
\hline \multicolumn{5}{|l|}{$\overline{\text { Nutrientes }^{(2)}}$} \\
\hline Matéria seca (MS, \%) & 53,00 & 57,00 & 58,00 & 60,00 \\
\hline Proteína bruta (\% de MS) & 16,20 & 17,40 & 17,60 & 17,80 \\
\hline Energia metabolizável (Mcal kg-1 de MS) & 2,89 & 2,96 & 2,97 & 3,00 \\
\hline Fibra em detergente neutro (\% de MS) & 27,70 & 24,70 & 24,20 & 23,10 \\
\hline Carboidratos não fibrosos (\% de MS) & 48,00 & 50,00 & 50,00 & 51,00 \\
\hline Extrato etéreo (\% de MS) & 6,30 & 6,80 & 6,80 & 6,90 \\
\hline Cálcio (\% de MS) & 0,47 & 0,44 & 0,42 & 0,40 \\
\hline Fósforo (\% de MS) & 0,46 & 0,47 & 0,47 & 0,47 \\
\hline \multicolumn{5}{|c|}{$\begin{array}{l}\text { (1)Composição do sal mineral (por quilograma do produto): } 190 \mathrm{~g}, \mathrm{Ca} ; 80 \mathrm{~g} \text {, } \\
\mathrm{P} ; 5 \mathrm{~g}, \mathrm{Mg} ; 17 \mathrm{~g}, \mathrm{~S} ; 140 \mathrm{~g}, \mathrm{Na} ; 215 \mathrm{~g}, \mathrm{Cl} ; 12 \mathrm{mg}, \mathrm{Se} ; 650 \mathrm{mg}, \mathrm{Cu} ; 826 \mathrm{mg} \text {, } \\
\text { Fe; } 2.400 \mathrm{mg}, \mathrm{Zn} ; 1.500 \mathrm{mg}, \mathrm{Mn} ; 150 \mathrm{mg}, \mathrm{I} ; 80 \mathrm{mg}, \mathrm{Co} ; 900 \mathrm{mg} \text {, Fl. } \\
\text { (2)Valores calculados pelo National Research Council (NRC) dos Estados } \\
\text { Unidos (Nutrient..., 2000) nível } 2 \text {. }\end{array}$} \\
\hline
\end{tabular}

Pesq. agropec. bras., Brasília, v.50, n.10, p.958-966, out. 2015 DOI: 10.1590/S0100-204X2015001000012 abate, as carcaças foram identificadas e seccionadas em duas metades semelhantes, que foram pesadas para a obtenção do peso de carcaça quente (PCQ) e do rendimento de carcaça quente (RCQ), determinado por: RQC $(\%)=(\mathrm{PCQ} / \mathrm{PVF}) 100$. A arroba produzida foi calculada em razão do ganho de peso total (GPVT), corrigido para o rendimento de carcaça quente (RCQ), determinado por: @ produzida=GPVT/15RCQ.

Uma hora após o abate, aferiu-se a temperatura da carcaça e, 24 horas post-mortem, mediu-se o pH final com o peagâmetro (Tradelab, Contagem, MG, Brasil), ambas realizadas à altura da terceira vértebra lombar. Posteriormente ao resfriamento, as meias carcaças foram seccionadas nas porções traseira, dianteira e ponta de agulha, e pesadas de acordo com a metodologia descrita por Müller (1987). Em seguida, o traseiro especial (traseiro-serrote) da meia carcaça esquerda foi seccionado nos seguintes cortes: filé-mignon, alcatra e maminha, picanha, contrafilé, filé da costela (noix), capa de filé, fraldinha, coxão mole, coxão duro, patinho, lagarto, músculo e aranha. Os cortes foram pesados integralmente e submetidos à limpeza, tendose retirado aparas e sebo, o que constitui os cortes de "açougue" e, em seguida, foram novamente pesados. A soma das massas de todos os cortes cárneos resultou no peso total dos cortes integrais e preparados (limpos), o que possibilitou o cálculo do rendimento total da meia carcaça.

Para obtenção da espessura de gordura subcutânea, realizou-se um corte no músculo longissimus, perpendicular à décima segunda e décima terceira costelas e, então, mediu-se a profundidade do tecido adiposo a três quartos de distância da borda medial do músculo, com paquímetro digital (Digimess Instrumentos de Precisão Ltda., São Paulo, SP, Brasil).

Uma amostra do músculo longissimus (thoracis e lumborum) foi extraída da meia carcaça esquerda, à altura da sexta até a décima segunda costela, para a utilização em análises posteriores. A porção correspondente à sexta costela foi seccionada e utilizada para determinação da composição química da carne, em que as características umidade, cinzas, proteína bruta e colágeno total, foram avaliadas por espectrometria de reflectância do infravermelho próximo (NIR), por meio do equipamento FoodScan Lab (Foss, Hillerød, Dinamarca), e os lipídeos totais foram determinados segundo a metodologia descrita por Bligh \& Dyer (1959), com uma mistura de clorofórmio e metanol. 
A seção do músculo longissimus entre a sétima e a nona costela foi dividido em bifes de $2,5 \mathrm{~cm}$ de espessura, que foram pesados e embalados a vácuo. Posteriormente, aferiram-se quatro medidas de cor, com auxílio de espectrofotômetro portátil CR 410 (Konica Minolta, Osaka, Japão), com esfera de integração, ângulo de $10^{\circ}$ e iluminante D65. Para a avaliação, adotou-se o sistema CIElab, que avalia a cor pela reflectância da luz em três dimensões: $\mathrm{L}^{*}$, luminosidade; $a^{*}$, variação entre a coloração vermelha $\left(+a^{*}\right)$ e verde $\left(-a^{*}\right) ; e, b^{*}$, variação entre a coloração amarela $\left(+b^{*}\right)$ a azul $\left(-b^{*}\right)$. Para análise da perda por cocção, os bifes foram descongelados durante 24 horas, em incubadoras para demanda bioquímica de oxigênio (BOD) a $4^{\circ} \mathrm{C}$. Os bifes foram pesados, embrulhados em papel alumínio e cozidos a $200^{\circ} \mathrm{C}$. Realizou-se o monitoramento da temperatura por meio de termômetros digitais, até as amostras atingirem $55^{\circ} \mathrm{C}$ de temperatura interna. Posteriormente, os bifes foram retirados do cozimento e mantidos em temperatura ambiente até atingirem a temperatura de $20^{\circ} \mathrm{C}$ e, então, foram pesados para o cálculo da perda por cocção (diferença entre o peso antes do cozimento e o peso após o cozimento).

Para a determinação da força de cisalhamento, utilizaram-se as amostras das análises de perda por cocção que, após a pesagem, permaneceram armazenadas por 24 horas a $2 \pm 2^{\circ} \mathrm{C}$. Decorrido o tempo, retiraram-se oito subamostras cilíndricas, de $2,5 \mathrm{~cm}$ de comprimento e $1,0 \mathrm{~cm}$ de diâmetro, paralelamente ao sentido das fibras. As amostras que apresentaram excesso de tecido conjuntivo foram descartadas. A força de cisalhamento foi determinada perpendicularmente à orientação das fibras musculares, com a lâmina Warner-Bratzler Shear Test adaptada ao texturômetro TA.TX plus (Stable Mycro Systems, Goldaming, Reino Unido). As velocidades utilizadas foram de $1,0 \mathrm{~mm} \mathrm{~s}^{-1}$, no pré-teste e no teste, e de $5,0 \mathrm{~mm} \mathrm{~s}^{-1}$ no pós-teste. Os resultados foram expressos em quilograma por centímetro quadrado. As médias das leituras de cada amostra foram utilizadas na análise estatística.

O procedimento univariate normal (SAS Institute, Cary, NC, EUA) foi utilizado para confirmar a normalidade dos dados, por meio do teste Shapiro-Wilk, tendo-se valores de probabilidades superiores a 0,90 . $\mathrm{Na}$ análise dos dados, o animal foi considerado como unidade experimental para todas as características estudadas, com exceção dos parâmetros de consumo e eficiência alimentar, para os quais utilizou-se a baia como unidade animal. O procedimento mixed (SAS Institute, Cary, NC, EUA) e o comando Satterthwaite foram utilizados para determinar os graus de liberdade do denominador, para testes de efeito fixo. Os dados foram analisados com o modelo de coeficientes aleatórios, em que se considerou o tratamento como efeito fixo, e o animal dentro de baia e a baia dentro de tratamento como efeitos aleatórios. Os dias de confinamento foram utilizados como covariável, para análise dos dados do peso corporal, para corrigir a autocorrelação de medidas repetidas no mesmo animal. As médias ajustadas pelo método dos quadrados mínimos foram usadas nas análises de comparações múltiplas, a $5 \%$ de probabilidade.

\section{Resultados e Discussão}

Não houve diferença, quanto ao peso vivo inicial (PVI) das novilhas, entre tratamentos, o que era esperado, já que esse foi o critério utilizado para a formação dos lotes (Tabela 2). A inclusão de simbióticos à dieta, adicionado ou não de monensina sódica, não influenciou o peso vivo final (PVF) nem e o peso de carcaça quente (PCQ), em comparação ao controle. Os pesos de abate e carcaça quente, obtidos no presente estudo, estão em conformidade com as exigências dos frigoríficos comerciais brasileiros, que preconizam o mínimo de $180 \mathrm{~kg}$ de carcaça equivalente a aproximadamente $340 \mathrm{~kg}$ de peso vivo (Gomide et al., 2009).

A ausência de efeito da associação de probióticos, prebióticos e monensina sódica, sobre o desempenho produtivo de bovinos de corte, também foi observada por Gomes et al. (2011). No presente estudo, a monensina sódica e sua associação aos simbióticos na dieta elevou o ganho de peso médio diário (GMD), em relação ao controle. Entretanto, a dieta com simbióticos não favoreceu a melhora do desempenho dos animais, em comparação aos demais tratamentos. Verificou-se que não houve potencialização do efeito da monensina quando associada aos simbióticos.

A adição ou não de simbióticos à monensina sódica na dieta não influenciou a ingestão de matéria seca (IMS), medida em quilograma por animal por dia, em comparação à dieta controle (Tabela 2). Porém, verificou-se que a associação da monensina sódica com simbióticos nas dietas melhorou a eficiência alimentar (EA) e a eficiência biológica (EB) das 
novilhas desses tratamentos, em comparação com as novilhas que receberam a dieta-controle. Contudo, Millen et al. (2013) relataram que animais confinados alimentados com dietas que continham monensina sódica apresentaram menor variação da IMS e maior número de refeições por dia. Sugere-se que a taxa de passagem pode ser diminuída, e o aproveitamento dos nutrientes melhorado, o que pode influenciar o aumento da EA e EB. Esse comportamento foi relatado por Tedeschi et al. (2003), por meio da compilação de 228 ensaios com bovinos em crescimento, mantidos em condições de confinamento. Os mesmos autores concluíram que o fornecimento de monensina sódica melhorou o GMD entre 1,6 e 1,8\% e aumentou a EA entre 6 e 7,5\%, o que é corroborado pelos resultados encontrados no presente estudo.

$\mathrm{O}$ rendimento de carcaça quente (RCQ) não foi influenciado pelos tratamentos. Estudo realizado por Goodrich et al. (1984) mostrou que o uso de monensina sódica não afeta as características de carcaça, entre as quais o RCQ. A média alcançada neste parâmetro, entre os tratamentos do presente estudo, foi satisfatória (51,9\%), quando se considera que, no Brasil, bovinos mestiços (Bos taurus $\times$ Bos indicus) que recebem dietas altamente energéticas e são terminados em confinamento apresentam RCQ entre 52 e 56\% (Rotta et al., 2009).

Não houve efeito de tratamento sobre a espessura de gordura subcutânea dos animais (Tabela 2). A espessura ideal para a proteção da carne deve ser de no mínimo $3 \mathrm{~mm}$, pois a gordura subcutânea é de extrema importância para a proteção de carcaça durante o resfriamento (Müller, 1987). Segundo Rotta et al. (2009) a espessura de gordura subcutânea de bovinos terminados em confinamento varia de 3 a $5 \mathrm{~mm}$. Entretanto, a elevada espessura de gordura subcutânea, encontrada nos animais do presente estudo $(9,4 \mathrm{~mm}$, na média dos tratamentos estudados), resulta de fatores genéticos da raça Angus (Prado et al., 2012).

A associação ou não de simbiótico à monensina sódica na dieta apresentou efeito apenas sobre o peso do corte comercial filé da costela (noix) integral e preparado, em comparação ao controle. $\mathrm{O}$ peso dos demais cortes integrais e preparados, a soma total dos cortes e o rendimento total da meia carcaça não foram influenciados pela inclusão dos aditivos na dieta (Tabela 3). Sugere-se que o efeito de promotor de crescimento dos aditivos utilizados favoreceram a maior deposição de proteína (carne) e lipídeos (gordura subcutânea e intramuscular), na porção torácica dos músculos longissimus dorsi, trapezius e rhomboideus, que compõem o corte comercial filé da costela (noix). A inclusão dos aditivos na dieta não influenciou os valores da proporção que cada corte do traseiro comercial (integral ou preparado) representa na meia carcaça esquerda (Tabela 4).

Não foram detectados efeitos de tratamento sobre as características de temperatura (1 hora) do músculo e pH final (24 horas) da carne (Tabela 5). Segundo Roça (2001), 24 horas após o desenvolvimento normal da glicólise muscular, o $\mathrm{pH}$ da carne deve se estabilizar entre 5,5 e 5,9. Em todos os tratamentos avaliados

Tabela 2. Desempenho, ingestão de matéria seca, eficiência alimentar e biológica, peso e rendimento de carcaça quente e espessura de gordura subcutânea de novilhas mestiças (Angus), em confinamento, alimentadas com dietas com ou sem inclusão de simbióticos (S) e monensina sódica $(\mathrm{M})^{(1)}$.

\begin{tabular}{|c|c|c|c|c|c|c|}
\hline \multirow[t]{2}{*}{ Variável } & \multicolumn{4}{|c|}{ Tratamento } & \multirow[t]{2}{*}{ EPM } & \multirow[t]{2}{*}{$\mathrm{p}$} \\
\hline & Controle & Simbiótico & Monensina & $\mathrm{S}+\mathrm{M}$ & & \\
\hline Peso vivo médio inicial $(\mathrm{kg})$ & 316,8 & 322,4 & 317,1 & 316,6 & 5,80 & 0,88 \\
\hline Peso vivo médio final $(\mathrm{kg})$ & 426,4 & 434,8 & 433,5 & 433,8 & 9,01 & 0,91 \\
\hline Ganho de peso médio diário (GMD, kg) & $1,31 b$ & $1,34 \mathrm{ab}$ & $1,39 \mathrm{a}$ & $1,39 \mathrm{a}$ & 0,05 & 0,04 \\
\hline Ingestão de matéria seca diária (IMS, kg por animal por dia) & 11,33 & 11,33 & 11,25 & 11,22 & 1,17 & 0,75 \\
\hline Arrobas produzidas & $3,85 b$ & $3,90 \mathrm{ab}$ & $4,00 \mathrm{a}$ & $4,01 \mathrm{a}$ & 0,16 & 0,04 \\
\hline Eficiência alimentar (GMD/IMS) & $0,12 b$ & $0,118 \mathrm{ab}$ & $0,12 \mathrm{a}$ & $0,12 \mathrm{a}$ & 0,01 & 0,01 \\
\hline Eficiência biológica (IMSPE/arrobas produzidas) & $256,4 b$ & $250,5 \mathrm{ab}$ & $241,5 \mathrm{a}$ & $239,4 \mathrm{a}$ & 10,66 & 0,03 \\
\hline Peso de carcaça quente $(\mathrm{kg})$ & 224,4 & 226,1 & 223,2 & 222,7 & 5,38 & 0,97 \\
\hline Rendimento de carcaça quente $(\%)$ & 52,6 & 52,0 & 51,5 & 51,3 & 0,47 & 0,18 \\
\hline Espessura de gordura subcutânea (mm) & 9,75 & 9,67 & 8,30 & 9,92 & 1,11 & 0,72 \\
\hline
\end{tabular}

${ }^{(1)}$ Médias seguidas de letras iguais não diferem, pelo teste LSD, a 5\% de probabilidade. S, dieta com inclusão de simbiótico; M, dieta com inclusão de monensina sódica; $\mathrm{S}+\mathrm{M}$, dieta com associação entre simbiótico e monensina sódica. IMSPE, ingestão de matéria seca no período experimental. 
no presente estudo, os valores de $\mathrm{pH}$ da carne (24 horas) não ultrapassaram os limites mínimo e máximo considerados adequados para a característica, o que indica que os animais receberam manejo correto e não foram submetidos a estresse no pré-abate (Christensen et al., 2011). A ausência de efeito desta variável está de acordo com outros estudos realizados com bovinos, em que a inclusão de diferentes aditivos naturais na dieta

Tabela 3. Peso dos cortes (integral e preparado) do traseiro comercial e rendimento total da meia carcaça esquerda de novilhas mestiças (Angus), em confinamento, alimentadas com dietas com ou sem inclusão de simbióticos (S) e monensina sódica $(\mathrm{M})^{(1)}$.

\begin{tabular}{|c|c|c|c|c|c|c|}
\hline \multirow[t]{2}{*}{ Corte } & \multicolumn{4}{|c|}{$\begin{array}{c}\text { Tratamento } \\
\end{array}$} & \multirow[t]{2}{*}{ EPM } & \multirow[t]{2}{*}{$\mathrm{p}$} \\
\hline & \multicolumn{4}{|c|}{ Controle Simbiótico Monensina S+M } & & \\
\hline & \multicolumn{4}{|c|}{ Peso do corte inteiro $(\mathrm{kg})$} & & \\
\hline Filé-mignon & 2,25 & 2,15 & 2,28 & 2,21 & 0,09 & 0,73 \\
\hline Alcatra + maminha & 3,63 & 3,43 & 3,40 & 3,48 & 0,23 & 0,89 \\
\hline Picanha & 2,28 & 2,47 & 2,47 & 2,54 & 0,15 & 0,66 \\
\hline Contrafilé & 6,25 & 5,50 & 6,12 & 6,11 & 0,30 & 0,33 \\
\hline Filé da costela (noix) & $2,08 \mathrm{~b}$ & $2,49 a$ & $2,50 \mathrm{a}$ & $2,57 \mathrm{a}$ & 0,13 & 0,04 \\
\hline Capa de filé & 1,58 & 1,56 & 1,64 & 1,73 & 0,12 & 0,75 \\
\hline Fraldinha & 2,66 & 2,68 & 2,96 & 2,89 & 0,16 & 0,46 \\
\hline Coxão mole & 7,45 & 7,69 & 7,63 & 7,75 & 0,25 & 0,86 \\
\hline Coxão duro & 4,13 & 4,21 & 4,05 & 4,17 & 0,18 & 0,94 \\
\hline Patinho & 4,35 & 4,58 & 4,59 & 4,62 & 0,16 & 0,58 \\
\hline Lagarto & 2,04 & 2,09 & 2,03 & 2,31 & 0,12 & 0,33 \\
\hline Músculo & 3,51 & 3,55 & 3,67 & 3,65 & 0,13 & 0,81 \\
\hline Aranha & 0,26 & 0,26 & 0,27 & 0,28 & 0,02 & 0,89 \\
\hline \multirow[t]{2}{*}{ Total } & 42,47 & 41,64 & 43,63 & 44,31 & 1,37 & 0,48 \\
\hline & \multicolumn{4}{|c|}{ Peso do corte preparado ${ }^{(2)}(\mathrm{kg})$} & & \\
\hline Filé-mignon & 1,49 & 1,50 & 1,51 & 1,51 & 0,07 & 0,99 \\
\hline Alcatra + maminha & 3,18 & 3,09 & 3,05 & 3,20 & 0,17 & 0,90 \\
\hline Picanha & 1,64 & 1,72 & 1,79 & 1,80 & 0,10 & 0,67 \\
\hline Contrafilé & 4,93 & 4,51 & 4,63 & 4,57 & 0,29 & 0,76 \\
\hline Filé da costela (noix) & $1,64 b$ & $1,90 \mathrm{a}$ & $1,92 \mathrm{a}$ & $1,89 \mathrm{a}$ & 0,08 & 0,04 \\
\hline Capa de filé & 1,16 & 1,23 & 1,12 & 1,33 & 0,09 & 0,36 \\
\hline Fraldinha & 1,84 & 1,95 & 2,14 & 2,07 & 0,10 & 0,21 \\
\hline Coxão mole & 6,96 & 6,93 & 6,89 & 7,13 & 0,30 & 0,94 \\
\hline Coxão duro & 3,76 & 3,81 & 3,66 & 3,76 & 0,17 & 0,94 \\
\hline Patinho & 4,02 & 4,16 & 4,17 & 4,23 & 0,20 & 0,89 \\
\hline Lagarto & 1,99 & 2,01 & 1,95 & 2,18 & 0,11 & 0,46 \\
\hline Músculo & 3,36 & 3,43 & 3,50 & 3,55 & 0,13 & 0,75 \\
\hline Aranha & 0,21 & 0,19 & 0,21 & 0,21 & 0,02 & 0,77 \\
\hline \multirow[t]{2}{*}{ Total } & 36,18 & 36,43 & 36,54 & 37,43 & 1,24 & 0,78 \\
\hline & \multicolumn{4}{|c|}{ Rendimento total da meia carcaça (\%) } & & \\
\hline Cortes inteiros & 76,81 & 74,68 & 77,49 & 77,37 & 1,34 & 0,20 \\
\hline Cortes preparados & 65,58 & 65,39 & 64,94 & 65,41 & 1,12 & 0,16 \\
\hline
\end{tabular}

${ }^{(1)}$ Médias seguidas de letras iguais não diferem, pelo teste LSD, a 5\% de probabilidade. ${ }^{(2)}$ Corte preparado, sem o peso de aparas e sebo. S, dieta com inclusão de simbiótico; M, dieta com inclusão de monensina sódica; $\mathrm{S}+\mathrm{M}$, dieta com associação entre simbiótico e monensina sódica. também não influenciou o pH final da carne (Zawadzki et al., 2011).

Não foram encontradas diferenças entre os tratamentos quanto à perda por cocção da carne. Tal resultado era esperado, pelo fato de não ter havido diferença entre o $\mathrm{pH}$ final da carne nos tratamentos e de essa característica ser diretamente relacionada à capacidade de retenção de água, com a quantidade de gordura, e a disposição das fibras no músculo (Huff-Lonergan \& Lonergan, 2005).

A força de cisalhamento da carne apresentou efeito do tratamento. Os menores valores foram obtidos

Tabela 4. Proporção dos cortes (integral e preparado) do traseiro comercial da meia carcaça esquerda de novilhas mestiças (Angus), em confinamento, alimentadas com dietas com ou sem inclusão de simbióticos (S) e monensina sódica (M).

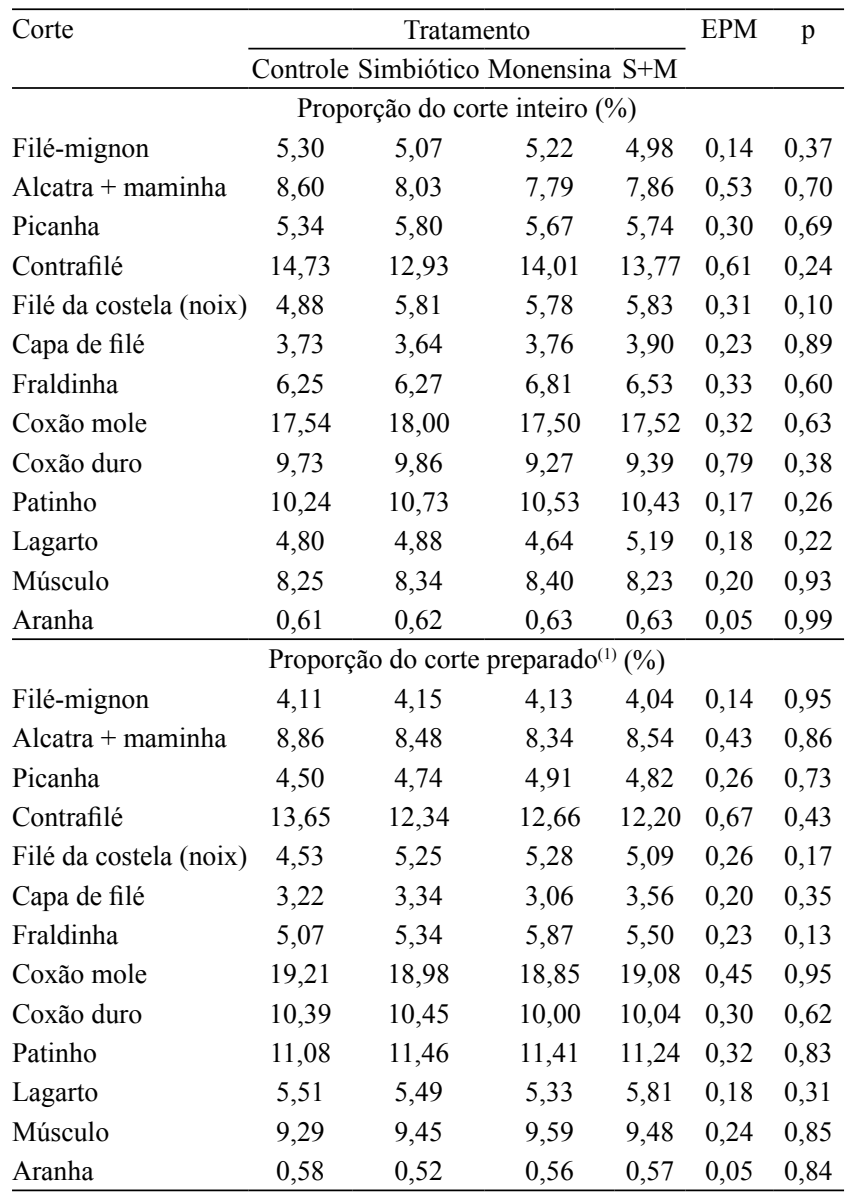

$\mathrm{S}$, dieta com inclusão de simbiótico; $\mathrm{M}$, dieta com inclusão de monensina sódica; $\mathrm{S}+\mathrm{M}$, dieta com associação entre simbiótico e monensina sódica. ${ }^{(1)}$ Corte preparado, sem o peso de aparas e sebo. 
na carne dos animais alimentados com a dieta com simbióticos, em comparação aos animais alimentados com o tratamento-controle. $\mathrm{O}$ uso dos aditivos em dietas com alta energia pode acarretar aumento do aporte de energia, em razão do aumento do propionato e da glicose sanguínea, resultantes das mudanças na população microbiana ruminal (Oliveira et al., 2007). Isso pode favorecer o depósito de gordura na carcaça, principalmente da gordura intramuscular, característica acentuada da raça Angus, o que proporciona maior maciez da carne.

O músculo longissimus não apresentou efeito do tratamento quanto aos teores de umidade, cinzas, proteína bruta e colágeno total. A ausência do efeito do tratamento sobre o colágeno total era esperada, visto que este componente do músculo é relacionado ao sexo, grupos raciais, idade (Cross et al., 1984), aptidões e precocidade (Christensen et al., 2011).

Os teores de lipídeos totais da carne foram maiores nos tratamentos com suplementação do que no controle (Tabela 5). Estas diferenças podem ser atribuídas à dieta, pois a natureza e a quantidade dos lipídeos armazenados no músculo são dependentes de condições de alimentação, digestão, absorção intestinal, metabolismo hepático e sistema de transporte de lipídeos (Geay et al., 2001), já que animais do mesmo grupo genético não diferem quanto à composição química do músculo, exceto pela quantidade de gordura que está diretamente relacionada à composição da dieta fornecida (Prado et al., 2008), fato observado no presente estudo.

Não se observou efeito de tratamento quanto à coloração da carne e da gordura (Tabela 6). Mancini

Tabela 5. Temperatura inicial do músculo e pH final da carne, perda por coç̧ão, força de cisalhamento e composição química do músculo longissimus dorsi de novilhas mestiças (Angus), em confinamento, alimentadas com dietas com ou sem inclusão de simbiótico $(\mathrm{S})$ e monensina sódica $(\mathrm{M})^{(1)}$.

\begin{tabular}{|c|c|c|c|c|c|c|}
\hline \multirow[t]{2}{*}{ Variável } & \multicolumn{4}{|c|}{ Tratamento } & \multirow[t]{2}{*}{ EPM } & \multirow[t]{2}{*}{$\mathrm{p}$} \\
\hline & Controle & Simbiótico & Monensina & $\mathrm{S}+\mathrm{M}$ & & \\
\hline Temperatura (1 hora) & 17,51 & 17,64 & 18,02 & 17,29 & 0,64 & 0,87 \\
\hline pH final (24 horas) & 5,73 & 5,68 & 5,65 & 5,71 & 0,04 & 0,41 \\
\hline Perda por cocção (\%) & 21,67 & 17,63 & 18,78 & 22,28 & 1,43 & 0,19 \\
\hline Força de cisalhamento $\left(\mathrm{kg} \mathrm{cm}^{-2}\right)$ & $5,73 \mathrm{a}$ & $3,67 \mathrm{~b}$ & $5,00 \mathrm{a}$ & $4,56 a b$ & 0,46 & 0,03 \\
\hline \multicolumn{7}{|l|}{ Composição química } \\
\hline Umidade $(\%)$ & 71,35 & 70,38 & 69,83 & 70,66 & 3,25 & 0,15 \\
\hline Cinzas $(\%)$ & 0,05 & 0,07 & 0,05 & 0,06 & 0,01 & 0,15 \\
\hline Proteína bruta (\%) & 23,09 & 22,75 & 23,30 & 23,22 & 0,93 & 0,12 \\
\hline Lipídeos totais $(\%)$ & $4,64 b$ & $5,70 \mathrm{a}$ & $6,41 \mathrm{a}$ & $5,77 \mathrm{a}$ & 0,28 & $<0,01$ \\
\hline Colágeno $\left(\mathrm{mg} \mathrm{g}^{-1}\right)$ & 1,46 & 1,45 & 1,51 & 1,43 & 0,02 & 0,20 \\
\hline
\end{tabular}

${ }^{(1)}$ Médias dos tratamentos seguidas por letras iguais não diferem, pelo teste LSD, a 5\% de probabilidade. C, tratamento-controle; S, dieta com inclusão de simbiótico; M, dieta com inclusão de monensina sódica; $\mathrm{S}+\mathrm{M}$, dieta com associação entre simbiótico e monensina sódica.

Tabela 6. Coloração da carne e da gordura de novilhas mestiças (Angus), em confinamento, alimentadas com dietas com ou sem inclusão de simbióticos e monensina sódica.

\begin{tabular}{|c|c|c|c|c|c|c|}
\hline \multirow[t]{2}{*}{ Medida da reflectância } & \multicolumn{4}{|c|}{ Tratamento } & \multirow[t]{2}{*}{ EPM } & \multirow[t]{2}{*}{$\mathrm{p}$} \\
\hline & Controle & Simbiótico & Monensina & $\mathrm{S}+\mathrm{M}$ & & \\
\hline \multicolumn{7}{|l|}{ Carne (pontos) } \\
\hline $\mathrm{L}^{*}$ & 37,67 & 38,18 & 37,64 & 38,93 & 0,50 & 0,25 \\
\hline$a^{*}$ & 18,25 & 18,71 & 18,56 & 19,13 & 0,38 & 0,42 \\
\hline $\mathrm{b}^{*}$ & 7,34 & 7,71 & 7,62 & 8,01 & 0,29 & 0,45 \\
\hline \multicolumn{7}{|l|}{ Gordura (pontos) } \\
\hline $\mathrm{L}^{*}$ & 67,01 & 67,60 & 68,27 & 68,62 & 0,54 & 0,17 \\
\hline$a^{*}$ & 4,89 & 5,05 & 5,44 & 4,99 & 0,43 & 0,82 \\
\hline$b^{*}$ & 13,13 & 13,34 & 13,47 & 12,59 & 0,30 & 0,18 \\
\hline
\end{tabular}

$\mathrm{S}$, dieta com inclusão de simbiótico, M, dieta com inclusão de monensina sódica; $\mathrm{S}+\mathrm{M}$, dieta com associação entre simbiótico e monensina sódica. L*, luminosidade; $a^{*}$, variação entre a coloração vermelha $\left(+a^{*}\right)$ a verde $\left(-a^{*}\right) ; b^{*}$, variação entre a coloração amarela $\left(+b^{*}\right)$ a azul $\left(-b^{*}\right)$. 
\& Hunt (2005) atribuíram os efeitos da dieta sobre a cor da carne e da gordura a qualquer alteração no armazenamento de glicogênio muscular, na taxa de refrigeração, ou acúmulo de antioxidantes. Entretanto, no presente estudo, nenhum efeito de tratamento foi atribuído às características de $\mathrm{pH}$ que pudessem modificar a coloração.

\section{Conclusões}

1. A inclusão de simbióticos, associados ou não à monensina sódica, na dieta de novilhas mestiças Angus em confinamento melhora o desempenho dos animais.

2. A adição de simbiótico à dieta de novilhas mestiças Angus em confinamento proporciona redução da força de cisalhamento da carne, o que melhora a sua qualidade.

\section{Agradecimentos}

À Coordenação de Aperfeiçoamento de Pessoal de Nível Superior (Capes), por concessão de bolsa; ao Sr. Alexandre Cominotte, graduando em Zootecnia da Universidade Estadual Paulista, Faculdade de Medicina Veterinária e Zootecnia (Unesp - FMVZ, Botucatu, $\mathrm{SP})$, pelo auxílio na realização deste trabalho; ao Dr. José Frederico Modolin, proprietário da Agropecuária Fazenda Paraíso (São João da Boa Vista, SP), por permitir a colaboração de seus funcionários e por conceder suas instalações e animais; e à Companhia Nacional de Nutrição Animal (Connan, Boituva, SP), pela doação do núcleo mineral.

\section{Referências}

BLIGH, E.G.; DYER, W.J. A rapid method of total lipid extraction and purification. Canadian Journal of Biochemistry Physiology, v.37, p.911-917, 1959. DOI: 10.1139/o59-099.

BRASIL. Ministério da Agricultura, Pecuária e Abastecimento (MAPA). Secretaria de Defesa Agropecuária. Instrução Normativa $\mathrm{n}^{\mathrm{o}} 3$, de 17 de janeiro de 2000. [Aprova o regulamento técnico de métodos de insensibilização para o abate humanitário de animais de açougue]. Diário Oficial [da] República Federativa do Brasil, Brasília, DF, 24 jan. 2000. Seção 1, p.14.

CHRISTENSEN, M.; ERTBJERG, P.; FAILLA, S.; SAÑUDO, C.; RICHARDSON, R.I.; NUTE, G.R.; OLLETA, J.L.; PANEA, B.; ALBERTÍ, P.; JUÁREZ, M.; HOCQUETTE, J.-F.; WILLIAMS, J.L. Relationship between collagen characteristics, lipid content and raw and cooked texture of meat from young bulls of fifteen European breeds. Meat Science, v.87, p.61-65, 2011. DOI: 10.1016/j.meatsci.2010.09.003.
COUTINHO FILHO, J.L.V.; PERES, R.M.; JUSTO, C.L. Produção de carne de bovinos contemporâneos, machos e fêmeas, terminados em confinamento. Revista Brasileira de Zootecnia, v.35, p.2043-2049, 2006. DOI: 10.1590/S1516-35982006000700023.

CROSS, H.R.; SCHANBACHER, B.D.; CROUSE, J.D. Sex, age, and breed related changes in bovine testosterone and intramuscular collagen. Meat Science, v.10, p.187-195, 1984. DOI: 10.1016/0309-1740(84)90021-4.

ESTADOS UNIDOS. Department of Agriculture. Foreign Agricultural Service. Countries \& Regions - Western Hemisphere - Brazil. 2015. Available at: $<$ http://www.fas.usda. gov/regions/brazil >. Accessed on: 3 mar. 2015.

GEAY, Y.; BAUCHART, D.; HOCQUETTE, J.-F.; CULIOLI, J. Effect of nutritional factors on biochemical, structural and metabolic characteristics of muscles in ruminants, consequences on dietetic value and sensorial qualities of meat. Reproduction, Nutrition, Development, v.41, p.1-26, 2001. DOI: 10.1051/ rnd:2001108.

GOMES, R.C.; ANTUNES, M.T.; SILVA, S.L.; LEME, P.R. Desempenho e digestibilidade de novilhos zebuínos confinados recebendo leveduras vivas e monensina. Archivos de Zootecnia, v.60, p.1077-1086, 2011. DOI: 10.4321/ S0004-05922011000400023.

GOMIDE, L.A. de M.; RAMOS, E.M.; FONTES, P.R. Tecnologia de abate e tipificação de carcaças. Viçosa: Ed. da UFV, 2009. $370 \mathrm{p}$.

GOODRICH, R.D.; GARRETT, J.E.; GAST, D.R.; KIRICK, M.A.; LARSON, D.A.; MEISKE, J.C. Influence of monensin on the performance of cattle. Journal of Animal Science, v.58, p.1484-1498, 1984.

GRAMINHA, C.V.; MARTINS, A.L.M.; FAIÃO, C.A.; BALSALOBRE, M.A.A. Aditivos na produção de bovinos confinados. [2007?]. Disponível em: <http://www.grupoapb.com. br/pdf/bovinos_confinados.pdf $>$. Acesso em: 3 mar. 2015.

HUFF-LONERGAN, E.; LONERGAN, S.M. Mechanisms of water-holding capacity of meat: the role of postmortem biochemical and structural changes. Meat Science, v.71, p.194-204, 2005. DOI: 10.1016/j.meatsci.2005.04.022.

ITO, R.H.; PRADO, I.N. do; ROTTA, P.P.; OLIVEIRA, M.G. de; PRADO, R.M. do; MOLETTA, J.L. Carcass characteristics, chemical composition and fatty acid profile of longissimus muscle of young bulls from four genetic groups finished in feedlot. Revista Brasileira de Zootecnia, v.41, p.384-391, 2012. DOI: 10.1590/ S1516-35982012000200022.

LADEIRA, M.M.; MACHADO NETO, O.R.; SANTAROSA, L. de C.; CHIZZOTTI, M.L.; OLIVEIRA, D.M. de; CARVALHO, J.R.R. de; ALVES, M.C.L. Desempenho, características de carcaça e expressão de genes em tourinhos alimentados com lipídeos e monensina. Pesquisa Agropecuária Brasileira, v.49, p.728-736, 2014. DOI: 10.1590/S0100-204X2014000900009.

MANCINI, R.A.; HUNT, M.C. Current research in meat color. Meat Science, v.71, p.100-121, 2005. DOI: 10.1016/j. meatsci.2005.03.003.

MILLEN, D.D.; RONCHESEL, J.R.; PARRA, F.S.; PACHECO, R.D.L.; MARTINS, C.L.; ARRIGONI, M.D.B. Anticorpos 
policlonais em dietas com alta inclusão de concentrado para bovinos confinados. Ciência Rural, v.43, p.1660-1667, 2013. DOI: $10.1590 / \mathrm{S} 0103-84782013005000109$.

MÜLLER, L. Normas para avaliação de carcaça e concurso de carcaças de novilhos. 2.ed. Santa Maria: UFSM, 1987. 31p.

NUTRIENT requirements of beef cattle. 7.ed. Washington: National Academy, 2000. 248p.

NUTRIENT requirements of dairy cattle. 7.ed. Washington: National Academy, 2001. 381p.

OLIVEIRA, M.V.M. de; LANA, R. de P.; EIFERT, E. da C.; LUZ, D.F.; PEREIRA, J.C.; PÉREZ, J.R.O.; VARGAS JUNIOR, F.M. de. Influência da monensina sódica no consumo e na digestibilidade de dietas com diferentes teores de proteína para ovinos. Revista Brasileira de Zootecnia, v.36, p.643-651, 2007. DOI: 10.1590/ S1516-35982007000300018.

PRADO, I.N. do; ARICETTI, J.A.; ROTTA, P.P.; PRADO, R.M. do; PEROTTO, D.; VISENTAINER, J.V.; MATSUSHITA, M. Carcass characteristics, chemical composition and fatty acid profile of the Longissimus muscle of bulls (Bos taurus indicus vs. Bos taurus taurus) finished in pasture systems. Asian-Australasian Journal of Animal Science, v.21, p.1449-1457, 2008. DOI: 10.5713/ajas.2008.80075.

PRADO, I.N. do; MAGGIONI, D.; ABRAHÃO, J.J. dos S.; VALERO, M.V.; PRADO, R.M. do; SOUZA, N.E. de. Meat quality of crossbred bulls fed with sorghum silage or sugar cane and slaughtered at two levels of fat thickness. Acta Scientiarum. Technology, v.34, p.337-344, 2012. DOI: 10.4025/actascitechnol. v34i3.15121.

RAIZEL, R.; SANTINI, E.; KOPPER, A.M.; REIS FILHO, A.D. dos. Efeitos do consumo de probióticos, prebióticos e simbióticos para o organismo humano. Revista Ciência e Saúde, v.4, p.66-74, 2011.

ROÇA, R. de O. Modificações post-mortem. [2001]. Disponível em: <http:/www.fca.unesp.br/Home/Instituicao/Departamentos/ Gestaoetecnologia/Teses/Roca105.pdf>. Acesso em: 12 jun. 2014.

ROTTA, P.P.; PRADO, R.M. do; PRADO, I.N. do; VALERO, M.V.; VISENTAINER, J.V.; SILVA, R.R. The effects of genetic groups, nutrition, finishing systems and gender of Brazilian cattle on carcass characteristics and beef composition and appearance: a review. Asian-Australasian Journal of Animal Sciences, v.22, p.1718-1734, 2009. DOI: 10.5713/ajas.2009.90071.

SAINZ, R.D. Nota técnica: BioFórmula Tecnologia Agropecuária Ltda. Goiânia: BioFórmula, 5 jul. 2010. 12p.

SILVA, D.J.; QUEIROZ, A.C. de. Análise de alimentos: métodos químicos e biológicos. 3.ed. Viçosa: Ed. da UFV, 2002. 235p.

STEIN, D.R.; ALLEN, D.T.; PERRY, E.B.; BRUNER, J.C.; GATES, K.W.; REHBERGER, T.G.; MERTZ, K.; JONES, D.; SPICER L.J. Effects of feeding propionibacteria to dairy cows on milk yield, milk components, and reproduction. Journal of Dairy Science, v.89, p.111-125, 2006. DOI: 10.3168/jds. S0022-0302(06)72074-4.

TEDESCHI, L.O.; FOX, D.G.; TYLUTKI, T.P. Potential environmental benefits of ionophores in ruminant diets. Journal of Environmental Quality, v.32, p.1591-1602, 2003. DOI: 10.2134/ jeq2003.1591.

ZAWADZKI, F.; PRADO, I.N.; MARQUES, J.A.; ZEOULA, L.M.; ROTTA, P.P.; SESTARI, B.B.; VALERO, M.V.; RIVAROLI, D.C. Sodium monensin or propolis extract in the diets of feedlot-finished bulls: effects on animal performance and carcass characteristics. Journal of Animal and Feed Sciences, v.20, p.16-25, 2011.

Recebido em 9 de março de 2015 e aprovado em 22 de julho de 2015 